eCommons@AKU

April 2016

\title{
Presenting features, treatment patterns and outcomes of patients with breast cancer in Pakistan: Experience at a university hospital
}

Kumar s

College of Medicine and Health Sciences, Sultan Qaboos University, Muscat, Sultanate of Oman,

Shaikh A.J

College of Medicine and Health Sciences, Sultan Qaboos University, Muscat, Sultanate of Oman,

Rashid YA

Aga Khan University

Masood N

Aga Khan University

Mohammed ATV

Aga Khan University

See next page for additional authors

Follow this and additional works at: http://ecommons.aku.edu/pakistan_fhs_mc_med_med Part of the Oncology Commons

\section{Recommended Citation}

s, K., J, S. A., YA, R., N, M., ATV, M., UZ, M., H, G. (2016). Presenting features, treatment patterns and outcomes of patients with breast cancer in Pakistan: Experience at a university hospital. Indian journal of Cancer, 53(2), 230-234.

Available at: http://ecommons.aku.edu/pakistan_fhs_mc_med_med/588 
Authors

Kumar s, Shaikh A. J, Rashid YA, Masood N, Mohammed ATV, Malik UZ, and Ghulam H 


\author{
Kumar S, Shaikh AJ', Rashid YA², Masood N², Mohammed ATV², Malik UZ', Haider G4, \\ Niamutullah $\mathrm{N}^{2}$, Khan $\mathbf{S}^{2}$ \\ Departments of Medicine, College of Medicine and Health Sciences, Sultan Qaboos University, Muscat, Sultanate of Oman, \\ ${ }^{2}$ Department of Oncology, The Aga Khan University Hospital, Karachi, Pakistan, ${ }^{1}$ Oncology Section, The Aga Khan University Hospital, \\ Nairobi, Kenya, ${ }^{3}$ Aga Khan Medical College, ${ }^{4}$ Medical Oncology, Jinnah Postgraduate Medical Institute, Karachi, Pakistan \\ Correspondence to: Dr. Shiyam Kumar, E-mail: bhagia1@yahoo.com
}

\begin{abstract}
BACKGROUND: Breast cancer is the most common cancer in Pakistani women. We report the presenting features, treatment patterns and survival of breast cancer from a University Hospital in Southern Pakistan and compare the data with international population based studies. MATERIALS AND METHODS: Medical records of patients diagnosed to have breast cancer between January 1999 and November 2008 were reviewed retrospectively. RESULTS: A total of 845 patients were identified. Median age of diagnosis was 48 years (range 18-92). Clinical stage was as follows: Stage I 9.9\%; Stage II 48.5\%; Stage III 26.2\%; Stage IV 13.8\%; data not available 1.5\%. Approximately, half (51.6\%) were estrogen receptor (ER) positive and $17.5 \%$ over-expressed Her2/neu. Nearly $23 \%$ patients received neo-adjuvant chemotherapy while $68.9 \%$ received adjuvant chemotherapy. Anthracycline based treatment was the most common treatment until 2003 while later on, patients also received taxanes and trastuzumab based therapy. Age, stage, tumor size, lymph node status, tumor grade, ER status, treatment with hormonal therapy and radiation were the major predictive factors for overall survival (OS). We report an impressive 5 year OS of $75 \%$, stage specific survival was $100 \%, 88 \%$ and $58 \%$ for Stages I, II and III respectively. CONCLUSION: The majority of patients present at a younger age and with locally advanced disease. However, short term follow-up reveals that the outcomes are comparable with the published literature from developed countries. Long-term follow-up and inclusion of data from population-based registries are required for accurate comparison.
\end{abstract}

Key Words: Breast cancer, chemotherapy, Pakistan, presenting features, survival

\section{Introduction}

Breast cancer remains the leading cause of cancer diagnosis and cancer-related death in women, world-wide. Mortality from breast cancer in the western hemisphere has recently showed a trend of decline, understandably this being a result attributable to effective screening and early detection programs, health awareness, access to health-care and a better health-care infrastructure. Developing world has on the other hand shown an increasing mortality, perhaps as a result of lack of availability of factors mentioned for the west, as well increasing "westernization" of the life-style. ${ }^{[1]}$ De novo geographical factors are also considered to be an important contributor for outcomes from breast cancer.

The incidence of breast cancer varies almost 10 fold if data were compared from different countries. ${ }^{[2]}$ Comparison of breast cancer data from various geographic locations is also considered to be important to understand underlying causes of disease or the reasons of death. ${ }^{[3]}$

Pakistan is a developing country, where health-care access is limited and fragmented. Population based registries report the age-standardized incidence of 9.1/100,000 for breast cancer, which is the highest reported from the area and is considerably higher than the much more populous neighboring India. ${ }^{[4]}$ The Aga Khan university Hospital is the largest private medical hospital, in the country and is located in the city of Karachi in Southern Pakistan. It receives patients from all over the country. ${ }^{[4]}$ The comprehensive cancer care services make it a reliable cancer care center in the country. ${ }^{[5]}$

\begin{tabular}{|l|l|}
\multicolumn{2}{|c|}{ Access this article online } \\
\hline Quick Response Code: & Website: \\
\hline & www.indianjcancer.com \\
\cline { 2 - 3 } & DOI: \\
\hline
\end{tabular}

This report covers different aspects of breast cancer observed at our institution, from demographic features, histopathological subtypes, treatment modalities, patterns and incidence of relapse and the treatment strategies in the metastatic setting, as well as the survival.

\section{Materils and Methods}

Data were analyzed retrospectively. The diagnoses are stored electronically using international classification of diseases version 9/10. Clinical data on consecutive patients admitted to the hospital between January 1999 and November 2008 and diagnosed to have invasive breast cancer were retrieved. Patients who were diagnosed with the disease earlier, but experienced relapse during the study period were also included. The hospital is one of the few hospitals providing comprehensive cancer care (surgery, chemotherapy, radiotherapy, palliative care, screening and molecular testing) in Pakistan. Majority of the patients included were diagnosed and treated at our hospital. For patients who had been initially diagnosed elsewhere, all specimens were reviewed by the pathology department for verification of diagnosis, immunohistochemistry (IHC) for estrogen receptor (ER), progesterone (PR) and Her2/neu status or fluorescence in situ hybridization (FISH) for Her2/neu gene, where indicated.

The medical records of all patients with a diagnosis of invasive breast cancer were reviewed and information was extracted on to a pre-designed database. Variables included age, gender, date of diagnosis, side of involvement; histopathological type of tumor; tumor size (clinical and pathological), lymph node involvement; number of lymph nodes removed, tumor grade, lymphovascular invasion, ER status, PR status, and Her2/neu status. Clinical and pathological stages were determined using the $6^{\text {th }}$ edition of American Joint Committee on Cancer (AJCC) manual. The date of last follow-up exam, date and site of relapse and date of death, when relevant were also recorded. The relapses were confirmed from the hospital records and during patient Indian Journal of Cancer | April-June 2016 | Volume 53 | Issue 2 
follow-up in clinics (not described for patients who lost to follow-up) and death was also confirmed either form the hospital records or through phone calls.

The data were censored at the date of last follow-up exam for each patient and relapse-free survival (RFS) was calculated from the date of diagnosis to the date of documented relapse. Overall survival (OS) was calculated from the date of diagnosis to the date of death or last follow-up/death where relevant. OS and RFS were determined using the method of Kaplan and Meir; Cox proportional hazard model was used to compare the survival between different stages. Univariate analysis was performed using the Chi-square test. The Cox model was used for multivariate analysis including all statistically significant factors on univariate analysis. Data were analyzed on statistical software package Statistical Package for the Social Sciences (version 16.0.2, SPSS, Chicago, IL, USA).

\section{Results}

\section{Clinical features}

A total of 845 patients were included diagnosed to have breast cancer in the study period while remaining 10 patients were diagnosed earlier, but included in the study as they received treatment for disease relapse. All but two were females; the median age at the diagnosis was 48 years (range 18-92 years). The majority of patients were between the ages 40 and 60 years $(n=515,60.9 \%)$, $15 \%$ had a family history of breast cancer, $45.7 \%$ of all patients were pre-menopausal while remaining had achieved menopause prior to diagnosis. Almost half of the patients $(50.5 \%)$ had left-sided breast cancer [Table 1].

\section{Pathological features}

Clinical and pathological stages are summarized in Table 2. Merely $9.9 \%$ patients presented with clinical Stage I disease (according to AJCC manual, $6^{\text {th }}$ edition), clinically, T4 disease was detected in $21.1 \%$ patients; only $12.1 \%$ of patients presented with clinical $\mathrm{Tl}$ lesion at the time of diagnosis. Likewise, $43.5 \%$ patients had clinically palpable nodes. Pathologically mean tumor size was $4.11 \mathrm{~cm}$ [Table 2]. Microscopically, $42.1 \%$ patients had involved lymph nodes, the mean number of involved nodes was 6 (range 0-33). More than $93 \%$ of the patients had infiltrating ductal carcinoma as the pathological diagnosis, while infiltrative lobular carcinoma $(2.7 \%)$ was the next common type. Almost a quarter $(25.9 \%)$ of patients had poorly differentiated cancer and lymphovascular invasion was seen in $15.1 \%$ specimens.

ER status was expressed by $51.6 \%$ tumors, whereas, PR was expressed by $44 \%$. Data on HER-2/neu status was available for $488(57.7 \%)$ patients; $13.1 \%$ patients expressed the protein using the IHC method, whereas, for another $(4.5 \%)$ patients the gene could be detected using FISH, leading to an overall expression rate of $17.6 \%$. Triple negative disease was diagnosed for $130(15.3 \%)$ patients [Table 3].

For patients presenting with Stage IV disease at presentation $(n=117,13.8 \%)$, bone was the most common site of distant disease $(n=74,63.2 \%)$, followed by lungs $(n=40,34.1 \%)$; more than one organ was involved in 34 patients $(29.0 \%)$.
Table 1: Clinical features of all patients treated during January 1999 to November 2008

\begin{tabular}{lc} 
Clinical characteristics & Number (\%) \\
\hline Gender & $843(99.8)$ \\
\hline Female & $2(0.2)$ \\
\hline Male & $178(21.1)$ \\
\hline Age & $515(60.9)$ \\
\hline$<40$ & $152(18)$ \\
\hline $46-60$ & \\
\hline$>60$ & $386(45.7)$ \\
\hline Menopausal status & $459(54.3)$ \\
\hline Pre-menopausal & $427(50.5)$ \\
\hline Menopausal & $393(46.5)$ \\
\hline Involved side & $25(3)$ \\
\hline Right &
\end{tabular}

Table 2: Clinical and pathological stage of all patients

\begin{tabular}{|c|c|c|}
\hline $\begin{array}{l}\text { Disease/tumor } \\
\text { charechtarestic }\end{array}$ & $\begin{array}{c}\text { Clinical } \\
\text { stage } n(\%)\end{array}$ & $\begin{array}{l}\text { Pathological } \\
\text { stage } n(\%)\end{array}$ \\
\hline \multicolumn{3}{|l|}{ Primary tumor } \\
\hline Tis & - & $1(0.1)$ \\
\hline T0 & - & $26(3.1)$ \\
\hline $\mathrm{T} 1$ & $102(12.1)$ & $178(21.1)$ \\
\hline $\mathrm{T} 2$ & $360(42.6)$ & 374 (44.3) \\
\hline T3 & $173(20.5)$ & $93(11.0)$ \\
\hline T4 & 185 (21.9) & $67(7.9)$ \\
\hline$N A^{*}$ & $25(3)$ & $106(12.6)$ \\
\hline \multicolumn{3}{|l|}{ Node status } \\
\hline NO & $441(52.2)$ & $365(43.2)$ \\
\hline N1 & $274(32.4)$ & $178(21.1)$ \\
\hline N2 & $86(10.2)$ & 97 (11.5) \\
\hline N3 & $8(0.9)$ & $80(9.5)$ \\
\hline$N A^{*}$ & $36(4.3)$ & $125(14.8)$ \\
\hline \multicolumn{3}{|l|}{ Overall stage } \\
\hline 0 & - & $23(2.8)$ \\
\hline I & $84(9.9)$ & $110(13.0)$ \\
\hline II & $410(48.5)$ & $355(42.0)$ \\
\hline III & $221(26.2)$ & $215(25.4)$ \\
\hline IV & 119 (14.1) & - \\
\hline$N A^{*}$ & $11(1.3)$ & $27(3.2)$ \\
\hline
\end{tabular}

\section{Treatment}

Of all patients with localized or locally advanced disease at presentation $(n=728,86.2 \%), 502(68.9 \%)$ were treated with adjuvant chemotherapy. For patients who presented with metastatic disease $(n=117,14.1 \%)$, palliative chemotherapy or hormonal therapy was administered to $95(81.2 \%)$ patients, 37 patients declined chemotherapy while four patients moved from the hospital before the initiation of treatment.

Out of 728 patients with non-metastatic disease on presentation, $265(36.4 \%)$ patients had locally advanced disease (cT3 or positive nodes clinically) and 195 (73.5\%) of these were treated with neo-adjuvant chemotherapy. 
Almost $2 / 3$ of patients $(61.9 \%)$ had modified radical mastectomy (MRM), while breast conservation surgery was performed in $21.2 \%$ and $5.1 \%$ were treated with simple mastectomy because of symptomatic advanced disease. Of 179 patients who had breast conservation surgery only 34 patients were administered neo-adjuvant chemotherapy, while out of 523 patients who had MRM 130 were treated with neo-adjuvant chemotherapy.

Majority of patients were treated with anthracycline based regimen $(n=500,59.1 \%)$ while $203(24.0 \%)$ received a taxane in addition to other cytotoxics. Amongst 149 patients expressing Her2/neu (by IHC or FISH), only 41 patients received trastuzumab [Table 4]. Only 24 patients completed one calendar year of treatment. Most declined and discontinued the treatment per cost of therapy. A total of 528 (62.5\%) patients were treated with radiation, in the adjuvant setting. Hormonal agents were prescribed to $450(53.2 \%)$ patients, tamoxifen was the most commonly prescribed drug $(n=357$, $79.3 \%$ ), anastrozole, letrozole and exemestane were prescribed to 54,38 and one patients respectively. Most of the patients $(n=273,60.6 \%)$ are/were taking their hormonal therapy actively until the date of last follow-up, 71 (15.7\%) have completed their 5 years of hormonal treatment, while remaining patients were switched to other hormonal agent or chemotherapy due to relapse, progressive disease, complication, intolerance, to extended aromitase inhibitors, or as switched therapy after 2-3 years of tamoxifen.

\section{Relapse patterns and survival}

All patients were followed at regular intervals in clinics, until the time of death or until they lost to follow-up with median follow-up of 29 months (range 1-224 months).

$135(135 / 728=18.5 \%)$ patients experienced relapse (local, loco-regional or distant). Distant recurrence was documented in $69(9.5 \%)$ while $22(3.0 \%)$ had a local recurrence. Bone, lungs and brain were the main sites of relapse. Most of the patients were treated with chemotherapy or radiotherapy while some patients were treated with combination treatment [Table 5]. Of all patients treated for relapsed disease, 32 progressed, 12 had a partial response,

\begin{tabular}{lc}
\hline Table 3: Receptor status for all patients & \\
\hline Receptor status & $n(\%)$ \\
\hline Estrogen receptor positive & $436(51.6)$ \\
\hline Estrogen receptor negative & $364(43.1)$ \\
\hline Estrogen receptor N/A & $45(5.3)$ \\
\hline Progesterone receptor positive & $372(44)$ \\
\hline Progesterone receptor negative & $418(49.5)$ \\
\hline Progesterone N/A & $54(6.4)$ \\
\hline Her2/neu status (by IHC) & $111(13.1)$ \\
\hline Her2/neu 3+ & $148(17.5)$ \\
\hline Her2/neu 2+ & $586(69.3)$ \\
\hline Her2/neu negative/not done & $38(4.5)$ \\
\hline Her2/neu status (by FISH) & $93(11)$ \\
\hline Her2/neu positive & $40(4.7)$ \\
\hline Her2/neu negative &
\end{tabular}

$\mathrm{N} / \mathrm{A}=$ Not available; $\mathrm{IHC}=$ Immunohistochemistry; FISH=Fluorescent in situ hybridization
5 had minimal response and 4 had stable disease while 1 had a complete response. 11 patients were treated after complete surgical removal of their relapsed disease and were in remission until the last follow-up.

Median RFS was 34 months while 5 year RFS was $19 \%$. Hormone receptor status $P=0.05)$, Her2/neu $(P \leq 0.01)$, tumor size (clinical or pathological $[P \leq 0.01]$ ), clinical node status $(P=0.002)$, clinical stage at presentation $(P \leq 0.01)$, number of involved nodes on pathological examination $(P=0.02)$, administration of neo-adjuvant and adjuvant chemotherapy, radiotherapy and hormonal therapy ( $\mathrm{P} \leq 0.01$ for each) were significant contributory factors for RFS.

At the time of last follow-up (July 31, 2010), 159 (18.8\%) patients have died due to disease, $26(3.1 \%)$ to causes not related to disease or treatment, $3(0.4 \%)$ because of treatment related toxicity. Median OS for all patients was 157 months with 5 year OS of $75 \%$, while it was $100 \%$, $88 \%$ and $58 \%$ for Stages I, II and III respectively. Median survival for Stage IV patients was 18 months [Figure 1].

Stage at presentation $(P \leq 0.01)$, clinical and pathological tumor size $(P \leq 0.01)$, clinical and pathological node status $(P \leq 0.01)$, tumor grade $(P \leq 0.01)$, lymphovascular invasion $(P=0.001)$, ER status $(P=0.02)$, radiation therapy $(\mathrm{P} \leq 0.01)$ and hormonal therapy $(\mathrm{P} \leq 0.01)$ were significant factors for OS on univariate analysis.

Clinical stage at presentation $(P \leq 0.01)$, pathological nodal status $(P \leq 0.01)$, ER status $(P \leq 0.01)$ were significant predictive factor for OS on multivariate analysis.

\section{Discussion}

The outcomes from breast cancer depend on multiple factors. Breast cancer biology including clinical stage, pathological subtype, hormonal and Her $2 /$ neu status are major contributors. Personal factors such as age, body mass index and race are also important. Socioeconomic factors, such as, access to the health-care, ability to afford appropriate treatment and facilities for screening and long-term follow-up and management are much less addressed. ${ }^{[6]}$



Figure 1: Overall survival for all patients according to stage

Indian Journal of Cancer | April-June 2016 | Volume 53 | Issue 2 


\begin{tabular}{|c|c|}
\hline Intent/chemotherapy regimen & No. (\%) \\
\hline \multicolumn{2}{|l|}{ Neo-adjuvant chemotherapy } \\
\hline $\mathrm{AC}$ & $106(12.5)$ \\
\hline $\mathrm{FAC} / \mathrm{FEC}$ & $31(3.6)$ \\
\hline TAC & $27(3.2)$ \\
\hline $\begin{array}{l}\text { Taxane (paclitaxel or docetaxel) } \\
\text { after anthracycline }\end{array}$ & $72(8.5)$ \\
\hline Trastuzumab* & $8(0.9)$ \\
\hline Hormonal treatment & $8(0.9)$ \\
\hline $\mathrm{TCH}$ & $3(0.4)$ \\
\hline \multicolumn{2}{|l|}{ Adjuvant chemotherapy } \\
\hline$A C$ & $109(12.8)$ \\
\hline FAC/FEC & $184(21.7)$ \\
\hline $\begin{array}{l}\mathrm{AC} / \mathrm{FAC} \rightarrow \text { paclitaxel } \\
(3 \text { weekly/dose dense/weekly) }\end{array}$ & $100(11.8)$ \\
\hline TAC & $20(2.3)$ \\
\hline CMF & $32(3.7)$ \\
\hline $\mathrm{AC} / \mathrm{FAC} \rightarrow$ docetaxel & $5(0.5)$ \\
\hline $\begin{array}{l}\text { Taxane (paclitaxel or docetaxel) } \\
\text { (after anthracycline) }\end{array}$ & $42(4.9)$ \\
\hline Trastuzumab (with or after taxane) & $39(4.6)$ \\
\hline \multicolumn{2}{|c|}{$\begin{array}{l}\text { A=Doxorubicin; } C=\text { Cyclophosphamide; } E=\text { Epirubicin; } F=\text { Fluorouracil; } \\
H=\text { Trastuzumab; M=Methotrexate; } T=\text { Docetaxel; *With or without taxane }\end{array}$} \\
\hline \multicolumn{2}{|l|}{ Table 5: Relapse patterns of patients } \\
\hline Relapse patterns & $\begin{array}{l}(n=728) \\
\text { No. }(\%)\end{array}$ \\
\hline \multicolumn{2}{|l|}{ Site of relapse } \\
\hline Distant relapse & $69(9.5)$ \\
\hline Local relapse & $22(3.0)$ \\
\hline Contra lateral relapse & $16(2.2)$ \\
\hline Loco-regional relapse & $9(1.2)$ \\
\hline Loco-regional and distant relapse & $13(1.8)$ \\
\hline Contra lateral and distant relapse & $2(0.2)$ \\
\hline Relapse while on adjuvant chemotherapy & $4(0.6)$ \\
\hline \multicolumn{2}{|l|}{ Site of first distant relapse } \\
\hline Bone & $17(12.59)$ \\
\hline Lungs & $14(10.37)$ \\
\hline Brain & $13(9.62)$ \\
\hline Liver & $6(4.4)$ \\
\hline Pleura & $5(3.7)$ \\
\hline Bone+lung & $9(6.6)$ \\
\hline Liver+lung+bone & $6(4.4)$ \\
\hline Carcinomatous meningitis & $3(2.2)$ \\
\hline Others & $15(11.1)$ \\
\hline
\end{tabular}

A comprehensive 10-year data is presented from Southern Pakistan. The data focuses on most common aspects of concern in breast cancer. The series reveal a younger mean age at presentation, i.e., 48 years as compared to 61 years reported in the surveillance epidemiology and end results (SEER) data. ${ }^{[7]}$ Our data conform to the data from Karachi cancer registry, a population based registry representing a sample population from all parts of Pakistan, which showed that more than $60 \%$ of breast cancer patients were below 50 years $^{[8]}$ and other studies reported form the country and surprisingly the age at presentation has remained almost same in last few decades. ${ }^{[9-11]}$ The age distribution curve is also similar to the data from most neighboring countries, including those from Arabian peninsula ${ }^{[12]}$ and the east Asia. ${ }^{[13]}$ A small number of patients $(9.9 \%)$ presented with Stage I disease, while nearly half $(48.5 \%)$ had Stage II disease, which seems to be similar with SEER data; where $60 \%$ of patients are diagnosed to have the localized disease, but differs widely in advanced stage disease as 5\% patients had Stage IV disease at presentation in SEER data as compared to $14.1 \%$ in our study. This highlights the changes in the trends perhaps set by screening programs and early stage detection. ${ }^{[14,15]}$ A diagnosis at an early stage is a strong negative predictor of recurrence and therefore improves the long-term survival. ${ }^{[9,16]}$

The number of patients presenting with Stage IV disease in our study were more than double compared with the western literature (14\% vs. $5 \%)$. Even for patients with non-metastatic disease a significant number had advanced tumor size (T4 lesions). Once staged our patients did not show vastly different pattern in terms of number and size of the lymph nodes involved and with the mean number of lymph nodes involved when compared with data presented by Carter et al. ${ }^{[17]}$ In comparison to contemporary data the hormone receptor status was found to be lower in our population with over half of all patient's tumors expressed ER, whereas, 44\% expressed PR receptors.

Most of our patients underwent MRM, with trends for breast conserving surgery relatively underutilized in most clinical situations which reflects the same trend in other institutions offering breast cancer surgery in the country. ${ }^{[11,18]}$ A high success rate for sentinel lymph node biopsy has been previously reported from our institute already. ${ }^{[19]}$

Neo-adjuvant chemotherapy was effectively utilized in almost three quarters of patients with locally advanced disease. A combination of adriamysin and cyclophohomide (AC) was the most commonly used chemotherapy regimen. Less than $3.6 \%$ of the patient received epirubicin. The reasons remain speculative; however, slightly higher unit cost compared to doxorubicin may have contributed. Not all patients could afford taxane based chemotherapy. Close to $24 \%$ managed to get a taxane combination when it was required either in the adjuvant or in the metastatic setting. Trastuzumab is now considered as an integral part of management regimen in Her2/neu over expressing breast cancers. A majority of our patients however could not afford to take adjuvant trastuzumab and in fact a very few actually received the drug for 1 year in the adjuvant setting. Financial difficulties leading to inability to receive standard adjuvant treatment affects the OS in developing countries, or where there is a lack of widespread health insurance system. Tamoxifen was the most favored hormonal agent prescribed. Regardless of the menopausal status, a trend which is consistent with practice observed by physicians world-wide and reported by us previously. ${ }^{[20]}$ Our patients showed a 3\% over all incidence of local relapse compared to international report of 5\% as reported in National Surgical Adjuvant Breast and Bowel Project NSABP-04 for adequately treated patient, with matching figures for distant recurrences as well. ${ }^{[21]}$ In our data series on a 10 year follow-up breast cancer, survival rates match the survival rates reported internationally and regionally [Figure 1]. ${ }^{[21,22]}$

The data presented has limitations, including a possible inherent bias of being from a single institution; it 
nevertheless represents a significant contribution as south Karachi, our sample population, is considered to be the habitat of a population representative of the whole of the country of Pakistan. ${ }^{[23]}$ Although the data presented here, may not be a complete representation of the prevailing trends of breast cancer in Pakistan, it however should contribute immensely to the existing scarce information on patterns and trends of the population from the subcontinent. The fact that the data set is perhaps the largest coming out from any single institution in Pakistan, makes it distinct. The patterns that have come to light by this study highlight the needs of further large scale population based studies to be done so that cost-effective guidelines on breast cancer care are made specific to the needs of this population.

Though the World Health Organization has mentioned about the age distribution of cancer for Pakistan and available cancer treatment facilities it does not mention the outcome at large and our data may help to establish or provide a platform for implementation of the guide lines for the breast cancer treatment in the country, but may also help to focus on the population screening in future. ${ }^{[24]}$

It should also be noted that our institution plays key role in cancer registry through its wide laboratory network across the country through, which large number of pathology specimen are sent to the pathology laboratory, which help to assess the cancer burden in the country. ${ }^{[4]}$

\section{Conclusion}

In conclusion, this data set presented from a 10 years follow-up of breast cancer patients at our institute suggests that breast cancer appears at relatively younger age and relatively advanced stage of the disease. The pathologic and biologic parameters show some distinct patterns from the region. Treatment modalities offered are according to the internationally accepted standards, but affordability and availability of the same remains restricted for most population. Despite these factors an overall trend of matching survival are found in comparison to regional and international data with regards to survival, however further large scale studies and comparative analysis are needed to improve the assessment of epidemiological and survival trends of our population.

\section{References}

1. Jakesz R. Breast cancer in developing countries: Challenges for multidisciplinary care. Breast Care (Basel) 2008;3:4-5.

2. Ziegler RG, Hoover RN, Pike MC, Hildesheim A, Nomura AM, West DW, et al. Migration patterns and breast cancer risk in Asian-American women. J Natl Cancer Inst 1993;85:1819-27.

3. Bray F, McCarron P, Parkin DM. The changing global patterns of female breast cancer incidence and mortality. Breast Cancer Res 2004;6:229-39.

4. Bhurgri Y, Bhurgri A, Nishter S, Ahmed A, Usman A, Pervez S, et al. Pakistan - Country profile of cancer and cancer control 1995-2004. J Pak
Med Assoc 2006;56:124-30

5. Bryant JH, Marsh DR, Khan KS, D'Souza R, Husein K, Aslam A, et al. A developing country's university oriented toward strengthening health systems: Challenges and results. Am J Public Health 1993;83:1537-43.

6. Komenaka IK, Martinez ME, Pennington RE Jr, Hsu CH, Clare SE, Thompson PA, et al. Race and ethnicity and breast cancer outcomes in an underinsured population. J Natl Cancer Inst 2010;102:1178-87.

7. Available from: http://seer.cancer.gov/statfacts/html/breast.html. July 19, 2013. [Last accessed on 2013 July 19].

8. Bhurgri Y, Kayani N, Faridi N, Pervez S, Usman A, Bhurgri H, et al. Patho-epidemiology of breast cancer in Karachi '1995-1997'. Asian Pac J Cancer Prev 2007;8:215-20.

9. Iqbal J, Bano K, Saeed A, Akram M, Aziz Z. Survival of women with locally advanced breast cancer at a teaching hospital in Lahore. J Pak Med Assoc 2010;60:721-5.

10. Malik AM, Pathan R, Shaikh NA, Qureshi JN, Talpur KA. Pattern of presentation and management of ca breast in developing countries. There is a lot to do. J Pak Med Assoc 2010;60:718-21.

11. Mamoon N, Sharif MA, Mushta--q S, Khadim MT, Jamal S. Breast carcinoma over three decades in northern Pakistan - Are we getting anywhere? J Pak Med Assoc 2009;59:835-8.

12. Kumar S, Burney IA, Al-Ajmi A, Al-Moundhri MS. Changing trends of breast cancer survival in sultanate of Oman. J Oncol 2011;2011:316243.

13. Shin HR, Joubert C, Boniol M, Hery C, Ahn SH, Won YJ, et al. Recent trends and patterns in breast cancer incidence among Eastern and Southeastern Asian women. Cancer Causes Control 2010;21:1777-85.

14. Miller AB, Baines CJ, To T, Wall C. Canadian National Breast Screening Study: 2. Breast cancer detection and death rates among women aged 50 to 59 years. CMAJ 1992; 147:1477-88.

15. Blanks RG, Moss SM, McGahan CE, Quinn MJ, Babb PJ. Effect of NHS breast screening programme on mortality from breast cancer in England and Wales, 1990-8: Comparison of observed with predicted mortality. BMJ 2000;321:665-9.

16. Galea MH, Blamey RW, Elston CE, Ellis IO. The Nottingham prognostic index in primary breast cancer. Breast Cancer Res Treat 1992;22:207-19.

17. Carter CL, Allen C, Henson DE. Relation of tumor size, lymph node status, and survival in 24,740 breast cancer cases. Cancer 1989;63:181-7.

18. Malik IA. Clinico-pathological features of breast cancer in Pakistan. J Pak Med Assoc 2002;52:100-4.

19. Zaman MU, Khan S, Hussain R, Ahmed MN. Sentinel lymph node scintigraphy and radioguided dissection in breast carcinoma: An initial experience at Aga Khan University Hospital. J Pak Med Assoc 2006;56:153-6.

20. Shaikh AJ, Kumar S, Raza S, Mehboob M, Ishtiaq O. Adjuvant hormonal therapy in postmenopausal women with breast cancer: Physician's choices. Int J Breast Cancer 2012;2012:849592.

21. Mamounas EP. NSABP breast cancer clinical trials: Recent results and future directions. Clin Med Res 2003;1:309-26.

22. French Adjuvant Study Group. Benefit of a high-dose epirubicin regimen in adjuvant chemotherapy for node-positive breast cancer patients with poor prognostic factors: 5-year follow-up results of French Adjuvant Study Group 05 randomized trial. J Clin Oncol 2001; 19:602-11.

23. Bhurgri Y, Bhurgri A, Hassan SH, Zaidi SH, Rahim A, Sankaranarayanan R, et al. Cancer incidence in Karachi, Pakistan: First results from Karachi Cancer Registry. Int J Cancer 2000;85:325-9.

24. WHO. Strategy for cancer prevention and control in the Eastern Mediterranean Region 2009-2013. Cairo, Egypt: World Health Organization, 2010.

How to cite this article: Kumar S, Shaikh AJ, Rashid YA, Masood N, Mohammed A, Malik UZ, et al. Presenting features, treatment patterns and outcomes of patients with breast cancer in Pakistan: Experience at a university hospital. Indian J Cancer 2016;53:230-4.

Source of Support: Nil. Conflict of Interest: None declared. 